\title{
Obesity prevalence in Colombian adults is increasing fastest in lower socio-economic status groups and urban residents: results from two nationally representative surveys
}

\author{
Nicole M Kasper ${ }^{1}$, Oscar F Herrán ${ }^{2}$ and Eduardo Villamor ${ }^{3, *}$ \\ 'Department of Environmental Health Sciences, University of Michigan School of Public Health, Ann Arbor, MI, \\ USA: ${ }^{2}$ School of Nutrition and Dietetics, Faculty of Health, Industrial University of Santander, Bucaramanga, \\ Colombia: ${ }^{3}$ Department of Epidemiology, University of Michigan School of Public Health, M5055 SPH II, 1415 \\ Washington Heights, Ann Arbor, Ml 48109-2029, USA
}

Submitted 19 July 2013: Final revision received 20 November 2013: Accepted 25 November 2013: First published online 2 January 2014

\begin{abstract}
Objective: Low- and middle-income countries are experiencing rises in the prevalence of adult obesity. Whether these increases disproportionately affect vulnerable subpopulations is unclear because most previous investigations were not nationally representative, were limited to women, or relied on self-reported anthropometric data which are subject to bias. The aim of the present study was to assess changes in the prevalence of obesity from 2005 to 2010 in Colombian adults; overall and by levels of sociodemographic characteristics.

Design: Two cross-sectional, nationally representative surveys.

Setting: Colombia.

Subjects: Men and women 18-64 years old ( $n 31105$ in 2005; $n 81115$ in 2010). Results: The prevalence of obesity (BMI $\geq 30 \mathrm{~kg} / \mathrm{m}^{2}$ ) was $13 \cdot 9 \%$ in 2005 and $16 \cdot 4 \%$ in 2010 (prevalence difference $=2 \cdot 7 \% ; 95 \%$ CI 1.9, 3.4\%). In multivariable analyses, obesity was positively associated with female sex, age, wealth, and living in the Pacific or National Territories regions in each year. In 2010, obesity was also associated with living in an urban area. The change in the prevalence of obesity from 2005 to 2010 varied significantly according to wealth; 5.0\% (95\% CI 3.3, $6 \cdot 7 \%)$ among the poorest and $0 \cdot 3 \%(95 \% \mathrm{CI}-1 \cdot 6,2 \cdot 2 \%)$ in the wealthiest $(P$, test for interaction $=0 \cdot 007)$, after adjustment. Obesity rates also increased faster in older than younger people $(P$, test for interaction $=0 \cdot 01)$, among people from urban compared with non-urban areas $(P$, test for interaction $=0 \cdot 06)$ and in adults living in the Atlantic region compared with others.

Conclusions: Adult obesity prevalence has increased in Colombia and its burden is shifting towards the poor and urban populations.
\end{abstract}

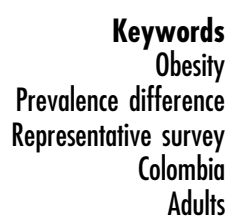

The global prevalence of obesity has been on the rise during the past couple of decades, especially in developing countries ${ }^{(1-3)}$. Between 1980 and 2008, mean BMI increased by $0.4 \mathrm{~kg} / \mathrm{m}^{2}$ per decade in men and $0.5 \mathrm{~kg} / \mathrm{m}^{2}$ per decade in women worldwide ${ }^{(4)}$. These increases have been steeper in Latin America, ranging from 0.6 to $1.4 \mathrm{~kg} / \mathrm{m}^{2}$ per decade ${ }^{(4)}$. In parallel with this shift in the BMI distribution, global obesity prevalence has doubled and by 2008 there were an estimated 502 million obese adults in the world, including $9 \cdot 8 \%$ of men and $13.8 \%$ of women $^{(4)}$. These changes are typically followed by rises in obesity-related chronic diseases, including type 2 diabetes and CVD, which may have devastating effects on the economies and health systems of developing countries $^{(5-7)}$. Whereas the obesity epidemic in adults from the USA appears to be levelling off ${ }^{(8)}$, it is uncertain whether the same is true for other regions in the Americas. In Brazil, the prevalence of obesity in adults aged 20 years or older increased from $11 \cdot 1 \%$ in $2002-2003$ to $14 \cdot 8 \%$ in 2008-2009 according to representative anthropometric surveys $^{(9,10)}$. Nevertheless, data from other countries have not been nationally representative, have focused only on women, or have relied on self-reported anthropometric data which are subject to bias.

Obesity is inversely associated with socio-economic status (SES) in developed countries, yet in poorer nations it tends to be related to wealth ${ }^{(11-13)}$. Survey data from women of childbearing age indicate that the prevalence of obesity grew more in the wealthiest than in the poorest groups of most low- and middle-income countries over the past two decades ${ }^{(11,13)}$. Nevertheless, in some lowerincome countries, rates of obesity are growing faster 
among adults in the lowest (compared with the highest) wealth and education groups ${ }^{(11,13,14)}$. It is hypothesized that this shift in the burden of obesity from the wealthier to the poorer may occur as countries reach a critical point in economic development ${ }^{(15)}$, partly as a consequence of lowered prices of unhealthy foods, unevenness in access to a healthy diet and urbanization ${ }^{(2,16-21)}$. However, few studies have examined recent changes in adult obesity within socio-economic strata using nationwiderepresentative data.

We examined the trends in obesity prevalence in Colombian adults from 2005 to 2010 using data from two consecutive national nutrition surveys. We estimated changes in obesity prevalence overall and by levels of sociodemographic characteristics, including sex, age, urbanicity, food security, wealth and region.

\section{Methods}

\section{Study population}

The Colombian National Nutrition Surveys (ENSIN) were conducted in 2005 and 2010 by the Colombian Institute of Family Welfare (Instituto Colombiano de Bienestar Familiar). Details on each survey have been published elsewhere $^{(22,23)}$. In brief, participants were selected to represent $99 \%$ of the country's population using a multistage stratified sampling scheme. All municipalities from the thirty-two departments in the country were grouped into strata based on similar geographic and sociodemographic characteristics. One municipality was randomly chosen from each stratum, with probability proportional to the population size. Clusters of about ten households each were then randomly chosen from within these strata and household members were invited to participate. The 2005 survey included 17740 households representing 1920 clusters from 209 strata. In the 2010 survey, 50670 households were included, representing 4987 clusters from 258 strata.

Consent for participation in the surveys was obtained by the Colombian Institute of Family Welfare prior to enrolment. The Health Sciences and Behavioral Sciences Institutional Review Board at the University of Michigan determined that analyses of these anonymized data were exempt from review.

\section{Data sources}

In both surveys, trained personnel administered questionnaires to the head of the household to obtain information on demographic characteristics, measures of food insecurity and wealth. Anthropometric measurements were obtained in all household members by research personnel who had been trained and standardized on the use of anthropometric techniques, with the use of calibrated instruments. Height was measured with the use of a height board (Shorr Productions LCC, Olney, MD, USA) in 2005 and a stadiometer (Diseños Flores S.R. Ltda, Bogota, Colombia) in 2010, to the nearest millimetre. Weight was measured on SECA Alpha model 770 scales in 2005 and on SECA 872 scales in 2010, to the nearest $100 \mathrm{~g}$.

The surveys included 76367 people in 2005 and 188599 in 2010 . For these analyses, we excluded participants $<18$ years of age ( $n 29668$ in 2005 and $n 74666$ in 2010) and women who reported being pregnant or who answered 'don't know' to a question on pregnancy status ( $n 1707$ in 2005 and $n 1793$ in 2010). In 2005, 4703 people aged 65 years or older were excluded. In 2010, no one aged 65 years or older was included in the survey. In addition, 9184 and 21025 people with missing data on height or weight were excluded in 2005 and 2010, respectively. Men were more likely than women to have missing anthropometric values, especially in 2005 (online supplementary material, Supplemental Table 1). The final analytic sample comprised 31105 adults aged 18-64 years in 2005 and 91115 in 2010.

The outcome of interest was obesity, defined as BMI $\geq 30 \mathrm{~kg} / \mathrm{m}^{2(24)}$. The primary correlate was year of survey (2005 or 2010). In addition, we considered sociodemographic variables as correlates of obesity within each survey, including age, sex, marital status, geographical region, urbanicity, food security and wealth. Urbanicity was categorized as living in urban settlements, in small villages or rural areas around a small town, or in rural dispersed areas distant from the nearest town. Food security status was measured using a modified version of the Community Childhood Hunger Identification Project $^{(25)}$, which has been previously adapted for and validated in a Colombian population ${ }^{(26)}$. There are twelve questions addressed to the head of the household regarding food insecurity experienced within the past $30 \mathrm{~d}$ due to lack of money for food. Only seven questions are asked to households without children. In 2010, additional questions were added to the survey; however, for comparability between years, we used only the questions and scale from 2005 to calculate food security for both survey years. Response options for each question no, seldom, sometimes or always - were assigned codes $0,1,2$ or 3 , respectively. Codes were added through all responses and the sum was categorized into a four-level variable: food secure $($ sum $=0$ ), mild food insecurity (sum $=1-7$ or 1-12 in households without or with children, respectively), moderate food insecurity ( $\mathrm{sum}=8-14$ or 13-24, respectively) or severe food insecurity (sum $\geq 15$ or $\geq 25$, respectively). Wealth was measured using an index designed for the international Demographic and Health Surveys ${ }^{(27)}$. This wealth index is constructed for each survey year from principal component analysis of a number of household assets, including type of flooring, number of bedrooms, type of toilet, mode of transportation, etc. The distribution of these variables is first standardized for the population and $Z$-scores for each variable are assigned to each household. Principal component analysis is then 
performed using the standardized variables; the first factor identified is used to define the wealth index as a continuous variable. A higher index represents more wealth. Each person is assigned the wealth index of their household. The continuous wealth index was categorized into quintiles according to its distribution among all survey participants, accounting for the complex survey design.

\section{Statistical analysis}

All analyses were conducted with the use of the complex survey design routines of the Stata statistical software package version 12 . We estimated weighted prevalences of obesity by year and within year by categories of sociodemographic predictors. Obesity prevalences were compared by levels of each correlate with the use of Rao-Scott $\chi^{2}$ tests and tests for linear trend for nominal and ordinal predictors, respectively; accounting for the complex survey design. We estimated adjusted prevalence ratios of obesity by levels of sociodemographic predictors in each year of the survey, with the use of multivariable Poisson regression models with the log-link and robust estimates of variance. In these models, adjustment variables included sex, age, marital status, food security, wealth, urbanicity and region of residence, categorized according to Table 1 . Finally, we examined the change in obesity prevalence from 2005 to 2010 overall and by levels of sociodemographic variables by estimating adjusted prevalence differences (PD) and 95\% confidence intervals in multivariable Poisson regression models. To determine whether changes in obesity prevalence from 2005 to 2010 differed significantly between levels of sociodemographic predictors, we tested cross-product

Table 1 Prevalence of obesity $\left(B M I \geq 30 \mathrm{~kg} / \mathrm{m}^{2}\right.$ ) in Colombian adults in the National Nutrition Surveys of 2005 and 2010

\begin{tabular}{|c|c|c|c|c|c|c|c|c|}
\hline & \multicolumn{4}{|c|}{2005} & \multicolumn{4}{|c|}{2010} \\
\hline & \multirow[b]{2}{*}{$N^{*}$} & \multicolumn{2}{|c|}{ Obeset } & \multirow[b]{2}{*}{$P$ value $\ddagger$} & \multirow[b]{2}{*}{$N^{*}$} & \multicolumn{2}{|c|}{ Obeset } & \multirow[b]{2}{*}{$P$ value } \\
\hline & & $\%$ & SE & & & $\%$ & SE & \\
\hline Sex & & & & $<0.0001$ & & & & $<0.0001$ \\
\hline Male & 12426 & $9 \cdot 0$ & $0 \cdot 4$ & & 39489 & $11 \cdot 5$ & $0 \cdot 2$ & \\
\hline Female & 18679 & $17 \cdot 0$ & $0 \cdot 4$ & & 51626 & $20 \cdot 0$ & $0 \cdot 2$ & \\
\hline Age (years) & & & & $<0.0001$ & & & & $<0.0001$ \\
\hline $18-24$ & 6818 & $3 \cdot 8$ & 0.3 & & 18959 & $5 \cdot 6$ & $0 \cdot 2$ & \\
\hline $25-34$ & 8053 & $10 \cdot 3$ & 0.5 & & 22766 & $13 \cdot 2$ & $0 \cdot 3$ & \\
\hline $35-44$ & 7228 & $16 \cdot 4$ & 0.6 & & 20625 & $18 \cdot 9$ & $0 \cdot 4$ & \\
\hline $45-54$ & 5589 & $22 \cdot 2$ & $0 \cdot 8$ & & 17431 & $23 \cdot 2$ & $0 \cdot 4$ & \\
\hline $55-64$ & 3417 & $22 \cdot 2$ & 0.9 & & 11334 & $25 \cdot 2$ & 0.5 & \\
\hline Marital status & & & & $<0.0001$ & & & & $<0.0001$ \\
\hline Married & 7788 & $19 \cdot 0$ & 0.6 & & 21561 & $21 \cdot 6$ & $0 \cdot 4$ & \\
\hline Living together & 10512 & $13 \cdot 9$ & 0.5 & & 33625 & $17 \cdot 5$ & 0.3 & \\
\hline Never married & 8059 & $6 \cdot 6$ & $0 \cdot 4$ & & 22358 & $8 \cdot 4$ & $0 \cdot 2$ & \\
\hline Separated & 3738 & $15 \cdot 6$ & $0 \cdot 8$ & & 11113 & $17 \cdot 7$ & $0 \cdot 4$ & \\
\hline Widowed & 998 & $25 \cdot 6$ & $2 \cdot 1$ & & 2436 & $28 \cdot 4$ & $1 \cdot 1$ & \\
\hline Food security & & & & 0.04 & & & & 0.001 \\
\hline Food secure & 17516 & $14 \cdot 5$ & $0 \cdot 4$ & & 47378 & $16 \cdot 9$ & $0 \cdot 2$ & \\
\hline Mild food insecurity & 7637 & $14 \cdot 1$ & $0 \cdot 6$ & & 27716 & $16 \cdot 2$ & $0 \cdot 3$ & \\
\hline Moderate food insecurity & 3455 & $12 \cdot 0$ & $0 \cdot 8$ & & 12640 & $15 \cdot 7$ & 0.5 & \\
\hline Severe food insecurity & 1080 & $13 \cdot 8$ & $1 \cdot 7$ & & 3381 & $14 \cdot 2$ & $0 \cdot 8$ & \\
\hline Wealth index quintile & & & & $<0.0001$ & & & & $<0.0001$ \\
\hline 1- poorest & 5463 & $8 \cdot 6$ & $0 \cdot 6$ & & 24765 & $12 \cdot 4$ & $0 \cdot 3$ & \\
\hline 2 & 8005 & $13 \cdot 2$ & $0 \cdot 6$ & & 21768 & $17 \cdot 1$ & $0 \cdot 4$ & \\
\hline 3 & 7061 & $14 \cdot 0$ & $0 \cdot 6$ & & 17905 & $16 \cdot 9$ & $0 \cdot 3$ & \\
\hline 4 & 5936 & $15 \cdot 8$ & $0 \cdot 7$ & & 14275 & $18 \cdot 0$ & $0 \cdot 4$ & \\
\hline 5 - wealthiest & 4640 & $16 \cdot 2$ & $0 \cdot 8$ & & 12402 & $17 \cdot 3$ & $0 \cdot 4$ & \\
\hline Urbanicity & & & & $<0.0001$ & & & & $<0.0001$ \\
\hline Urban area & 24927 & $14 \cdot 6$ & $0 \cdot 4$ & & 64314 & $17 \cdot 1$ & $0 \cdot 2$ & \\
\hline Small rural village & 3549 & $12 \cdot 9$ & $0 \cdot 8$ & & 16051 & $15 \cdot 3$ & 0.5 & \\
\hline Dispersed rural area & 2629 & $10 \cdot 0$ & 0.9 & & 10750 & $13 \cdot 6$ & $0 \cdot 4$ & \\
\hline Region & & & & 0.004 & & & & $<0.0001$ \\
\hline Atlantic & 7305 & $12 \cdot 5$ & 0.5 & & 20263 & $16 \cdot 6$ & $0 \cdot 4$ & \\
\hline Oriental & 3516 & $14 \cdot 5$ & $0 \cdot 8$ & & 13220 & $17 \cdot 2$ & $0 \cdot 4$ & \\
\hline Central & 6132 & $13 \cdot 6$ & 0.5 & & 23001 & $16 \cdot 6$ & $0 \cdot 3$ & \\
\hline Pacific & 4386 & $15 \cdot 3$ & $0 \cdot 8$ & & 13678 & $17 \cdot 4$ & $0 \cdot 4$ & \\
\hline Bogotá & 1510 & $13 \cdot 2$ & $1 \cdot 0$ & & 5785 & $14 \cdot 1$ & 0.5 & \\
\hline National Territories & 8256 & $18 \cdot 3$ & $0 \cdot 8$ & & 15168 & $17 \cdot 8$ & 0.5 & \\
\hline
\end{tabular}

${ }^{\star} N$ refers to the total sample frequency for each category. In 2005, fifteen people and in 2010, twenty-nine people had missing values for marital status and were excluded from the descriptive statistics of marital status. In 2005, 2063 people had missing values for food insecurity and were excluded from the descriptive statistics of food insecurity.

tPercentage of obesity and standard error are weighted to represent the Colombian population.

$\ddagger P$ values are from the Rao-Scott $\chi^{2}$ test for sex, marital status, urban/rural and region. For age, food security and wealth index, $P$ values represent a test for trend from unadjusted Poisson regression models with obesity as the outcome and a variable representing categories of the ordinal correlate as a continuous predictor. 
(interaction) terms between year and categories of each predictor with the use of adjusted Wald tests. In supplemental analyses, we examined associations of obesity with year and sociodemographic characteristics stratified by sex.

\section{Results}

Mean BMI in 2005 and 2010 was $25 \cdot 2(\mathrm{sE} 0 \cdot 1) \mathrm{kg} / \mathrm{m}^{2}$ and $25 \cdot 7(\mathrm{SE} 0 \cdot 0) \mathrm{kg} / \mathrm{m}^{2}$, respectively; the difference between the years was $0.5 \mathrm{~kg} / \mathrm{m}^{2}\left(95 \%\right.$ CI $\left.0.4,0.6 \mathrm{~kg} / \mathrm{m}^{2}\right)$. There were no major changes in the shape of the BMI distribution between the survey years overall or by sex (Fig. 1). Prevalence of obesity in 2005 and 2010 was 13.9 (SE $0 \cdot 3) \%$ and $16 \cdot 4(\operatorname{SE~} 0 \cdot 2) \%$, respectively. The PD was $2 \cdot 7 \%(95 \%$ CI $1 \cdot 9,3 \cdot 4 \%)$.
In both years, the prevalence of obesity was highest in women, participants aged 55-64 years, those without food insecurity or who were in the highest quintiles of the wealth index, and people living in urban areas or in the National Territories region (Table 1). Some of these associations differed between women (online supplementary material, Supplemental Table 2) and men (online supplementary material, Supplemental Table 3). For example, the positive associations of wealth index and food security with obesity in both survey years were stronger in men than women. Similarly, the higher prevalence of obesity in urban compared with rural areas in both survey years was apparent in men but not in women.

Next, we examined the associations of sociodemographic factors and prevalence of obesity in each survey year after adjusting for potential confounding (Table 2). In both years,
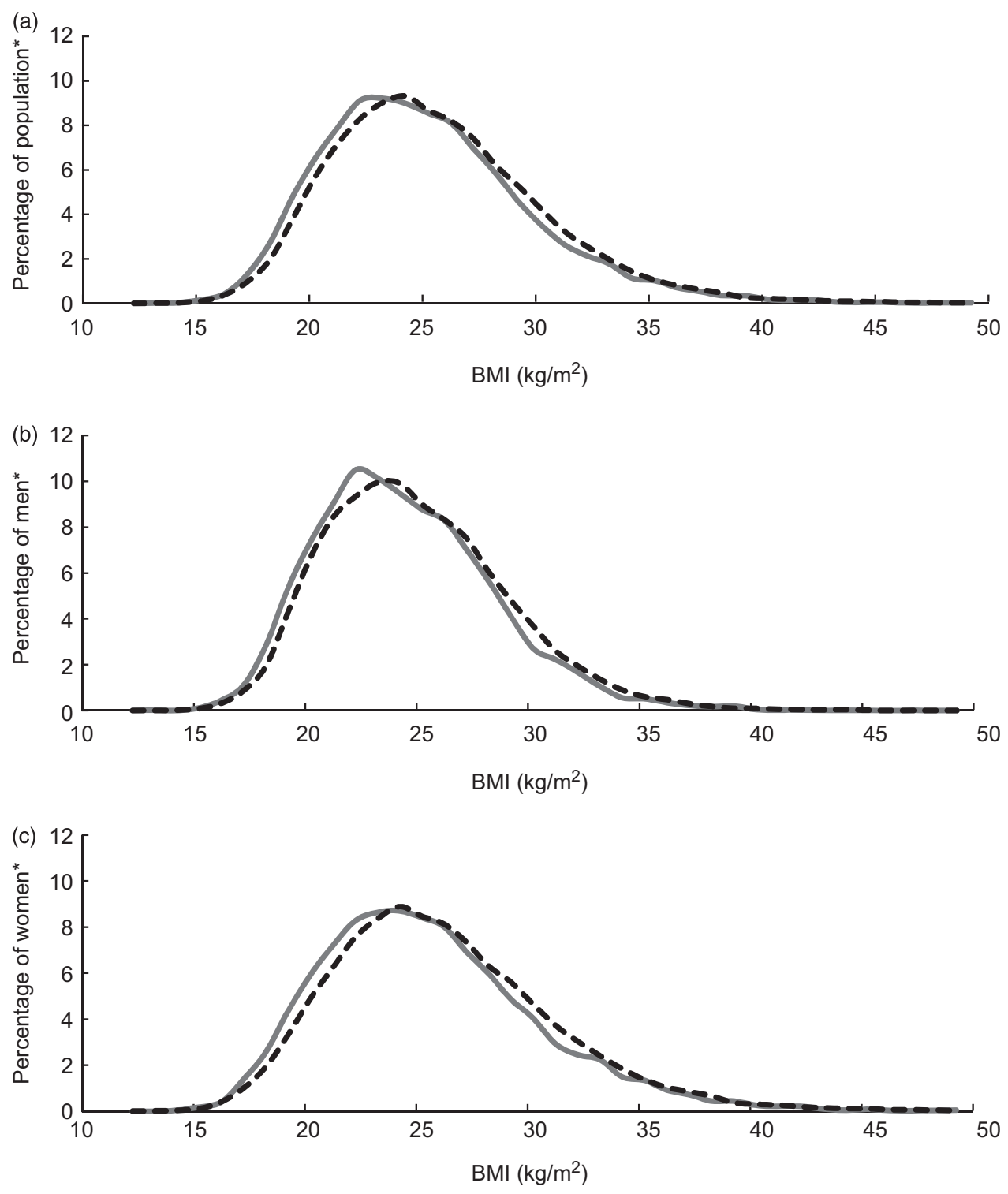

Fig. 1 BMI distribution in Colombian adults in 2005 (-) and 2010 (--): (a) total population; (b) men; (c) women. *Represents the percentage of population for a one unit change in BMI 
Table 2 Adjusted prevalence ratios for obesity $\left(B M I \geq 30 \mathrm{~kg} / \mathrm{m}^{2}\right)$ in Colombian adults in 2005 and 2010

\begin{tabular}{|c|c|c|c|c|}
\hline & \multicolumn{2}{|c|}{2005} & \multicolumn{2}{|c|}{2010} \\
\hline & $\mathrm{PR}^{*}$ & $95 \% \mathrm{Cl}$ & PR & $95 \% \mathrm{Cl}$ \\
\hline \multicolumn{5}{|l|}{ Sex } \\
\hline Male & 0.56 & $0.50,0.61$ & 0.60 & $0.57,0.62$ \\
\hline Female & $1 \cdot 00$ & & 1.00 & \\
\hline \multicolumn{5}{|l|}{ Age (years) } \\
\hline $18-24$ & 0.44 & $0.35,0.54$ & 0.50 & $0.46,0.54$ \\
\hline $25-34$ & 1.00 & & $1 \cdot 00$ & \\
\hline $35-44$ & 1.50 & $1 \cdot 33,1 \cdot 69$ & $1 \cdot 36$ & $1 \cdot 29,1 \cdot 44$ \\
\hline $45-54$ & $2 \cdot 01$ & $1 \cdot 78,2 \cdot 27$ & 1.67 & $1 \cdot 59,1.77$ \\
\hline $55-64$ & $2 \cdot 00$ & $1 \cdot 77,2 \cdot 27$ & $1 \cdot 85$ & $1 \cdot 74,1.96$ \\
\hline \multicolumn{5}{|l|}{ Marital status } \\
\hline Married & 0.99 & $0.90,1.09$ & 0.98 & $0.93,1.02$ \\
\hline Living together & $1 \cdot 00$ & & $1 \cdot 00$ & \\
\hline Never married & 0.65 & $0.56,0.74$ & 0.66 & $0.62,0.71$ \\
\hline Separated & 0.81 & $0.72,0.92$ & 0.78 & $0.74,0.83$ \\
\hline Widowed & $1 \cdot 02$ & $0 \cdot 85,1 \cdot 23$ & 0.98 & $0.90,1.07$ \\
\hline \multicolumn{5}{|l|}{ Food security } \\
\hline Food secure & $1 \cdot 00$ & & $1 \cdot 00$ & \\
\hline Mild food insecurity & 1.07 & $0.97,1 \cdot 17$ & 0.99 & $0.95,1.03$ \\
\hline Moderate food insecurity & 1.00 & $0 \cdot 86,1 \cdot 15$ & 0.98 & $0.91,1.04$ \\
\hline Severe food insecurity & $1 \cdot 18$ & $0.90,1.55$ & 0.89 & $0 \cdot 79,1 \cdot 00$ \\
\hline \multicolumn{5}{|l|}{ Wealth index quintile } \\
\hline 1 - poorest & $1 \cdot 00$ & & $1 \cdot 00$ & \\
\hline 2 & $1 \cdot 71$ & $1 \cdot 39,2 \cdot 10$ & $1 \cdot 33$ & $1 \cdot 24,1 \cdot 43$ \\
\hline 3 & $1 \cdot 84$ & $1 \cdot 45,2 \cdot 35$ & $1 \cdot 31$ & $1 \cdot 21,1 \cdot 42$ \\
\hline 4 & $2 \cdot 06$ & $1 \cdot 62,2 \cdot 62$ & $1 \cdot 38$ & $1 \cdot 27,1 \cdot 50$ \\
\hline 5 - wealthiest & $2 \cdot 12$ & $1 \cdot 66,2 \cdot 71$ & $1 \cdot 32$ & $1 \cdot 20,1 \cdot 44$ \\
\hline \multicolumn{5}{|l|}{ Urbanicity } \\
\hline Urban area & 1.00 & & 1.00 & \\
\hline Small rural village & $1 \cdot 11$ & $0.96,1.29$ & 0.92 & $0 \cdot 85,1 \cdot 00$ \\
\hline Dispersed rural area & 1.09 & $0 \cdot 84,1 \cdot 41$ & 0.86 & $0.79,0.93$ \\
\hline \multicolumn{5}{|l|}{ Region } \\
\hline Atlantic & $1 \cdot 01$ & $0 \cdot 90,1 \cdot 14$ & $1 \cdot 06$ & $1 \cdot 00,1 \cdot 12$ \\
\hline Oriental & 1.07 & $0.94,1 \cdot 21$ & 1.05 & $0 \cdot 99,1 \cdot 11$ \\
\hline Central & 1.00 & & $1 \cdot 00$ & \\
\hline Pacific & $1 \cdot 16$ & $1 \cdot 02,1 \cdot 32$ & $1 \cdot 08$ & $1 \cdot 02,1 \cdot 15$ \\
\hline Bogotá & 0.92 & $0.78,1.09$ & 0.80 & $0.74,0.86$ \\
\hline National Territories & $1 \cdot 42$ & $1 \cdot 26,1 \cdot 60$ & $1 \cdot 18$ & $1 \cdot 10,1 \cdot 27$ \\
\hline
\end{tabular}

obesity was positively associated with female sex, age, and living in the Pacific or National Territories regions. Whereas in 2005 the association of wealth with obesity followed a dose-response gradient, in 2010 the prevalence of obesity was equally higher in wealth quintiles 2 to 5 as compared with the lowest quintile. By contrast, while living in rural areas (small rural villages or dispersed rural areas) was not related to the prevalence of obesity in 2005, it was associated with a lower prevalence compared with urban areas in 2010.

Finally, we examined the change in the prevalence of obesity from 2005 to 2010 by estimating prevalence differences in categories of each predictor, from multivariable regression models (Fig. 2). The change in the prevalence of obesity was significantly higher in persons aged 55-64 years than in younger adults ( $P$, test for interaction with year $=0 \cdot 01$ ). There was also in inverse relationship between wealth and change in obesity prevalence ( $P$, test for interaction with year $=0 \cdot 007$ ) After adjustment, the prevalence difference between 2010 and 2005 in the poorest group was $5 \cdot 0 \%$ (95\% CI 3.3, $6.7 \%)$ whereas there was not a significant change in the wealthiest group ( $\mathrm{PD}=0 \cdot 3 \% ; 95 \% \mathrm{CI}-1 \cdot 6,2 \cdot 2 \%)$. The change in obesity prevalence was higher in people living in an urban environment (PD $=3 \cdot 3 \% ; 95 \%$ CI 2.5, 4.1\%), compared with that in people living in small rural towns $(\mathrm{PD}=0.4 \% ; 95 \% \mathrm{CI}-1 \cdot 7,2 \cdot 6 \%)$ or in dispersed rural areas $(\mathrm{PD}=-0 \cdot 3 \% ; 95 \% \mathrm{CI}-3 \cdot 4,3.3 \% ; P$, test for interaction with year $=0 \cdot 06)$. The increase in obesity prevalence also varied significantly by region $(P$, test for interaction with year $=0 \cdot 02)$. The highest increase was observed in the Atlantic region ( $\mathrm{PD}=3 \cdot 8 \%$; $95 \% \mathrm{CI} 2 \cdot 5$, $5 \cdot 2 \%$ ), followed by the Central ( $\mathrm{PD}=3 \cdot 0 \% ; 95 \%$ CI $1 \cdot 8$, $4 \cdot 3 \%$ ), Oriental ( $\mathrm{PD}=3 \cdot 0 \%$; $95 \%$ CI $1 \cdot 4,4 \cdot 5 \%$ ), Pacific $(\mathrm{PD}=2 \cdot 2 \% ; 95 \%$ CI $0 \cdot 5,4 \cdot 0 \%)$, Bogotá $(\mathrm{PD}=0 \cdot 8 \%$; 


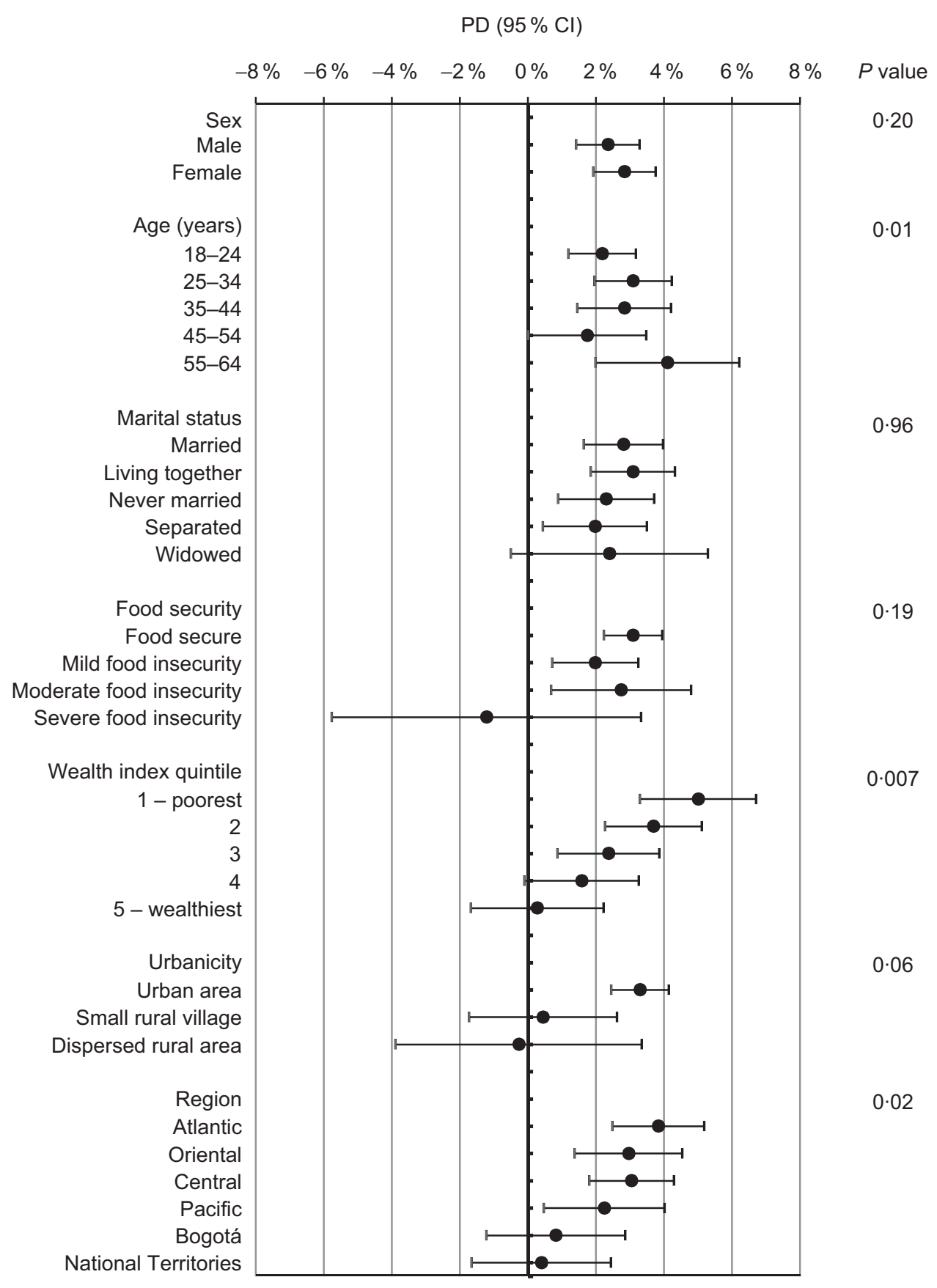

Fig. 2 Adjusted obesity prevalence differences (PD) between 2005 and 2010 among Colombian adults. Prevalence differences ( $\bullet$ ) and $95 \%$ confidence intervals (represented by horizontal lines) are from Poisson regression models with obesity as the dichotomous outcome and predictors that included indicator variables for each sociodemographic correlate, year 2010 (2005 as reference) and cross-product (interaction) terms between year and the indicator variables of the correlate. In addition, each model was adjusted for all other sociodemographic correlates including indicator variables for male sex (female as reference), age (four indicators with '25-34' as reference), marital status (four indicators with 'living together' as reference), food security (three indicators with 'food secure' as reference), wealth index quintile (four indicators with ' 1 - poorest' as reference), urbanicity (two indicators with 'urban area' as reference) and region of residence (five indicators with 'Central' as reference). The complex sampling survey design was taken into account in all multivariable regression models. $P$ values are from adjusted Wald tests for interaction between year and categories of each sociodemographic characteristic

$95 \% \mathrm{CI}-1 \cdot 2,2 \cdot 8 \%)$ and National Territories (PD $=0 \cdot 4 \%$; $95 \% \mathrm{CI}-1 \cdot 6,2 \cdot 4 \%)$. When the results were stratified by sex, the differential increases in obesity prevalence by age, urbanicity and region were more evident in women (online supplementary material, Supplemental Fig. 1) than men (online supplementary material, Supplemental Fig. 2). However, the greatest increase among the poorer than the wealthier remained apparent in both women and men. 


\section{Discussion}

The average BMI of Colombian adults increased by $0.5 \mathrm{~kg} / \mathrm{m}^{2}$ between 2005 and 2010 , equivalent to a rate of $1 \cdot 0 \mathrm{~kg} / \mathrm{m}^{2}$ per decade, which is twice the mean BMI increase rate that has been noted globally, but on pace with the increase seen in the Latin American region ${ }^{(4)}$. Obesity prevalence has increased in both adult men and women; however, this rise has not been uniform. Although obesity was positively related to wealth in both years, the fastest increments have occurred in people of the lowest SES and among those living in urban areas. Whereas obesity was most prevalent in the National Territories region in both years, the rise between the surveys was lowest in that region and highest in the Atlantic, so that regional differences seen in 2005 appeared to be levelling out by 2010 .

Obesity was associated with high SES in both 2005 and 2010. In settings at early stages of the nutrition transition, a positive relationship of SES with obesity might be explained by increased access to processed foods and more sedentary lifestyles among the better-off. While wealth was related to obesity in each survey year, there was a strong gradient in prevalence change between survey years by wealth index. The prevalence increased by $5 \%$ in the poorest people but there was virtually no change in the wealthiest. This trend was more apparent in women than in men and could partly explain the lack of a clear correlation between obesity and wealth in 2010 among females. The shift in the burden of obesity from the richer to the poorer has been documented as countries move through economic development and appears to affect women before men, consistent with the results of our study. It could be due to increased availability of low-cost obesogenic foodstuffs of poor nutritional quality that are consumed by the least affluent ${ }^{(18)}$. In a review of studies from fourteen countries, Monteiro et al. found that the reversal of the association between obesity and SES occurs when countries have a per capita GNP (gross national product) of about \$US 2500 in 2004 (approximately \$US 3072 in 2013) and that this occurs at a lower GNP per capita for women than men ${ }^{(15)}$. This shift may be occurring in Colombia at a higher GNP level (from about \$US 3281 in 2005 to \$US 4895 in 2010, in 2013 US dollars) ${ }^{(28)}$.

We found that obesity prevalence was highest in urban areas in 2005 and 2010 and that prevalence was growing faster in urban than rural areas, when controlling for sex, age, wealth, food security and other covariates. Decreased physical activity and increased consumption of high-energy foods related to urbanization have been identified as major contributors to the rise in obesity prevalence worldwide ${ }^{(2)}$. Between 2005 and 2010, imports of food products in Colombia doubled ${ }^{(29)}$, potentially enhancing exposure to a more 'Western' diet which has been associated with risk of obesity ${ }^{(30)}$. An additional explanation for the greater increase in obesity among urban than rural inhabitants is that the change is mediated by improvements in $\mathrm{SES}^{(31)}$. This may not necessarily be the case in Colombia, where social and political unrest continued to displace a substantial number of people from rural to urban areas to engross the poorer groups in the cities during the period between surveys.

Of note, food security status was positively related to the prevalence of obesity in both survey years. Nevertheless, after adjustment for wealth and other potential confounders the association was attenuated and became non-statistically significant. The role of food security on obesity is controversial and possibly depends on a country's stage through the nutrition transition. In countries at more advanced stages, severe food insecurity has been related to increased prevalence of obesity ${ }^{(32,33)}$ whereas in countries at earlier stages, it is related to underweight $^{(34)}$. In our case, the attenuation of a positive relationship of food security with obesity after adjustment suggests that it may have been confounded by SES.

The geographical gradient of the recent changes in obesity prevalence is noteworthy. The highest increase was observed in the Atlantic region, followed by the Oriental, Central and Pacific regions, with virtually no change in Bogotá or the National Territories. The Atlantic region's prevalence was lowest in 2005; thus, regression to the mean could be an explanation for the greatest shift observed there. Nevertheless, causal explanations cannot be ruled out. These might include region-specific changes in food availability or physical activity patterns related to drifts in socio-economic or environmental conditions during this period. Future research into potential explanations for the geographic variation in changes in obesity prevalence might inform potential public health interventions to prevent further increases.

A major strength of the current study is that it assessed changes in prevalence of obesity using measured height and weight data from nationally representative samples of both adult men and women. Recent changes in the burden of obesity within socio-economic strata had not been carefully characterized in this region. The majority of prior studies of obesity trends relied on data from the Demographic and Health Surveys, which are limited to women of childbearing age; the WHO World Health Surveys, which rely on self-reported heights and weights; or small, non-representative samples ${ }^{(4,11,14,35)}$. One limitation of the study was that a sizeable group was excluded for lack of data on height or weight. If the probability of inclusion in the analyses was related to both survey year and BMI status, results could be affected by selection bias. Men were excluded more frequently in 2005 due to lack of anthropometric data, but it is uncertain whether the prevalence of obesity differed between participating and non-participating male subjects.

In sum, the prevalence of obesity among Colombian adults increased by about 3\% between 2005 and 2010 . This increase has disproportionately affected the poorest 
people in the country. The implications of these changes on rates of obesity-related chronic diseases require careful surveillance. Whether similar trends exist in children is a critical next step in the research agenda. Identifying both immediate and contextual causes of the recent increases in obesity rates will allow appropriate interventions and policy to be implemented to decrease their impact.

\section{Acknowledgments}

Sources of funding: These secondary analyses of the Colombian National Nutrition Surveys did not receive specific financial support. The Colombian National Nutrition Surveys were conducted by the Colombian Institute of Family Welfare and the National Institute of Health of Colombia with support from the Colombian Ministry of Health and Social Protection. Funding sources did not play any role in the design, conduct, analyses or interpretation of the present study. Conflicts of interest: None of the authors have any conflicts of interest or financial disclosures. Ethics statement: The research was conducted in accordance with guidelines laid down by the Declaration of Helsinki. The Health Sciences and Behavioral Sciences Institutional Review Board at the University of Michigan exempted from review all research on these anonymized data sets. Authors' contributions: N.M.K. performed the statistical analyses and wrote the initial draft of the manuscript. O.F.H. procured the data and participated in the study design and data interpretation. E.V. designed the research, contributed to data analyses and interpretation, and had primary responsibility for the final content. All authors have read and approved the final version of the manuscript. Acknowledgements: The authors thank Dr Brady West at the University of Michigan's Center for Statistical Consultation and Research for guidance in analyses of complex survey designs.

\section{Supplementary material}

To view supplementary material for this article, please visit http://dx.doi.org/10.1017/S1368980013003418

\section{References}

1. Kelly T, Yang W, Chen CS et al. (2008) Global burden of obesity in 2005 and projections to 2030. Int J Obes (Lond) 32, 1431-1437.

2. Malik VS, Willett WC \& Hu FB (2013) Global obesity: trends, risk factors and policy implications. Nat Rev Endocrinol 9, 13-27.

3. Prentice AM (2006) The emerging epidemic of obesity in developing countries. Int J Epidemiol 35, 93-99.

4. Finucane MM, Stevens GA, Cowan MJ et al. (2011) National, regional, and global trends in body-mass index since 1980: systematic analysis of health examination surveys and epidemiological studies with 960 country-years and $9 \cdot 1$ million participants. Lancet $377,557-567$.
5. Hossain P, Kawar B \& Nahas ME (2007) Obesity and diabetes in the developing world - a growing challenge. $N$ Engl J Med 356, 213-215.

6. Misra A \& Khurana L (2008) Obesity and the metabolic syndrome in developing countries. J Clin Endocrinol Metab 93, 11 Suppl. 1, S9-S30.

7. Whitlock G, Lewington S, Sherliker P et al. (2009) Bodymass index and cause-specific mortality in 900000 adults: collaborative analyses of 57 prospective studies. Lancet 373, 1083-1096.

8. Flegal KM, Carroll MD, Kit BK et al. (2012) Prevalence of obesity and trends in the distribution of body mass index among US adults, 1999-2010. JAMA 307, 491-497.

9. Instituto Brasileiro de Geografia e Estatística (2004) Pesquisa de orçamentos familiares 2002-2003: Análise da disponibilidade domiciliar de alimentos e do estado nutricional no Brasil. Rio de Janeiro: IBGE.

10. Instituto Brasileiro de Geografia e Estatística (2010) Pesquisa de orçamentos familiares 2008-2009: Antropometria e estado nutricional de crianças, adolescentes $e$ adultos no Brasil. Rio de Janeiro: IBGE.

11. Jones-Smith JC, Gordon-Larsen P, Siddiqi A et al. (2012) Is the burden of overweight shifting to the poor across the globe? Time trends among women in 39 low- and middle-income countries (1991-2008). Int J Obes (Lond) 36, 1114-1120.

12. Pampel FC, Denney JT \& Krueger PM (2012) Obesity, SES, and economic development: a test of the reversal hypothesis. Soc Sci Med 74, 1073-1081.

13. Subramanian SV, Perkins JM, Ozaltin E et al. (2011) Weight of nations: a socioeconomic analysis of women in low- to middle-income countries. Am J Clin Nutr 93, 413-421.

14. Fleischer NL, Roux AVD \& Hubbard AE (2012) Inequalities in body mass index and smoking behavior in 70 countries: evidence for a social transition in chronic disease risk. $A m \mathrm{~J}$ Epidemiol 175, 167-176.

15. Monteiro CA, Moura EC, Conde WL et al. (2004) Socioeconomic status and obesity in adult populations of developing countries: a review. Bull World Health Organ 82, 940-946.

16. Drewnowski A (2009) Obesity, diets, and social inequalities. Nutr Rev 67, Suppl. 1, S36-S39.

17. Drewnowski A \& Popkin BM (1997) The nutrition transition: new trends in the global diet. Nutr Rev 55, 31-43.

18. Drewnowski A \& Specter SE (2004) Poverty and obesity: the role of energy density and energy costs. Am J Clin Nutr 79, 6-16.

19. Larson NI, Story MT \& Nelson MC (2009) Neighborhood environments: disparities in access to healthy foods in the US. Am J Prev Med 36, 74-81.

20. Popkin BM (2003) The nutrition transition in the developing world. Dev Policy Rev 21, 581-597.

21. Popkin BM (2004) The nutrition transition: an overview of world patterns of change. Nutr Rev 62, 7 Pt 2, S140-S143.

22. Instituto Colombiano de Bienestar Familiar (2005) Encuesta Nacional de la Situacion Nutricional en Colombia 2005. Bogotá: Instituto Colombiano de Bienestar Familiar.

23. Instituto Colombiano de Bienestar Familiar (2011) Encuesta Nacional de la Situacion Nutricional en Colombia 2010. Bogotá: Instituto Colombiano de Bienestar Familiar.

24. World Health Organization (1995) Physical Status: The Use and Interpretation of Anthropometry. Report of a WHO Expert Committee. WHO Technical Report Series no. 854. Geneva: WHO

25. Wehler CA, Scott RI \& Anderson JJ (1992) The community childhood hunger identification project: a model of domestic hunger - demonstration project in Seattle, Washington. J Nutr Educ 24, Suppl. 1, S29-S35.

26. Alvarez MC, Estrada A, Montoya EC et al. (2006) Validation of a household food security scale in Antioquia, Colombia. Salud Publica Mex 48, 474-481. 
27. Rutstein SO \& Johnson K (2004) The DHS Wealth Index. DHS Comparative Reports no. 6. Calverton, MD: ORC Macro.

28. United Nations Statistics Division (2013) Country Profile: Colombia. http://data.un.org/CountryProfile.aspx?crName= COLOMBIA (accessed April 2013).

29. Food and Agriculture Organization of the United Nations (2013) Colombia Overview, FAOSTAT. http://faostat3.fao.org/ home/index.html\#VISUALIZE_BY_AREA (accessed April 2013).

30. Hawkes C, Chopra M \& Friel S (2003) Globalization, trade, and the nutrition transition. In Globalization and Health: Pathways, Evidence and Policy, pp. 235-262 [R Labonté, T Schrecker, C Packer et al., editors]. New York: Taylor and Francis.

31. Neuman M, Kawachi I, Gortmaker S et al. (2013) Urban-rural differences in BMI in low- and middle-income countries: the role of socioeconomic status. Am J Clin Nutr 97, 428-436.

32. Kac G, Velásquez-Melendez G, Schlüssel MM et al. (2012) Severe food insecurity is associated with obesity among Brazilian adolescent females. Public Health Nutr 15, 1854-1860.

33. Leung CW, Williams DR \& Villamor E (2012) Very low food security predicts obesity predominantly in California Hispanic men and women. Public Health Nutr 15, 2228-2236.

34. Isanaka S, Mora-Plazas M, Lopez-Arana S et al. (2007) Food insecurity is highly prevalent and predicts underweight but not overweight in adults and school children from Bogota, Colombia. J Nutr 137, 2747-2755.

35. Martorell R, Khan LK, Hughes ML et al. (2000) Obesity in women from developing countries. Eur J Clin Nutr 54, $247-252$. 